\title{
Exhaled Electronic Cigarette Emissions: What's Your Secondhand Exposure?
}

\author{
Jonathan Thornburg, Quentin Malloy, Seung-Hyun Cho, \\ William Studabaker, and Youn Ok Lee
}

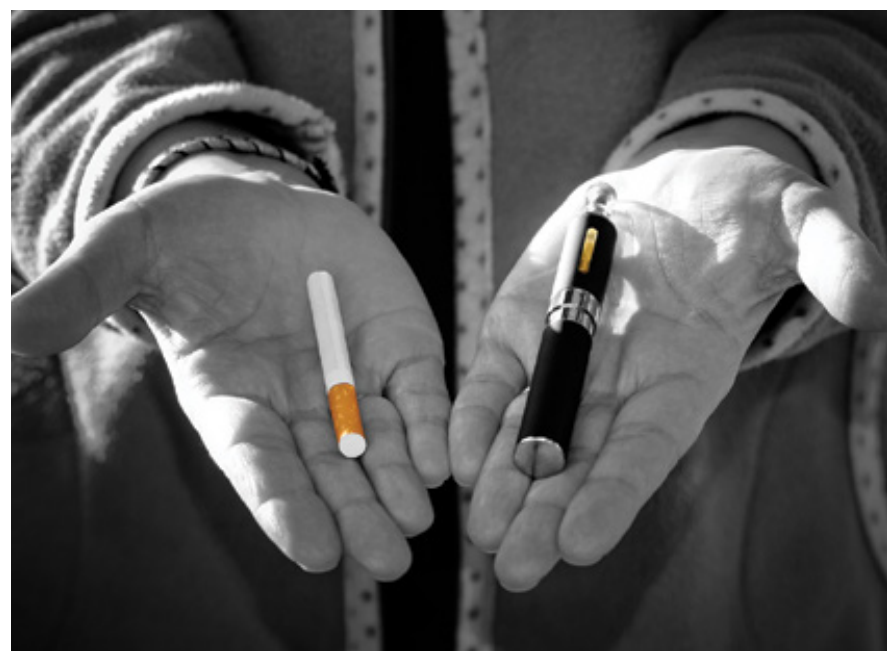

\section{Current Knowledge}

Electronic cigarettes (e-cigarettes) are nicotine-delivering consumer products designed to closely mimic the experience of smoking conventional cigarettes. The courts have determined e-cigarettes to be tobacco products, and the Food and Drug Administration has proposed deeming them a tobacco product. E-cigarettes are currently unregulated. Very little is known about the health effects associated with their use. As e-cigarette use rapidly proliferates in the United States, research is needed to determine potential health risks posed by emissions from e-cigarettes. Currently, little scientific evidence on the toxicant exposures posed by e-cigarette use is available, particularly for a non-user's secondhand exposures in public places.

Few studies have been published that assess secondhand exposure to e-cigarette emissions or have been performed using realistic exposure conditions. E-cigarette emissions contain nicotine, with its known pharmacological effects on neurotransmitters in the central and sympathetic nervous system that lead to addiction. E-cigarette emissions also contain numerous chemicals the FDA considers "generally

\section{Key Findings}

- Electronic cigarettes are a rapidly growing business with annual sales doubling yearly to \$1 billion in 2013.

- Little scientific evidence exists on secondhand exposures to the aerosols and vapors exhaled by the user of an electronic cigarette.

- A non-user may be exposed to aerosol particles smaller than 1000 nanometers, similar in size to tobacco smoke and diesel engine smoke. The exact size distribution depends on the chemical composition of the electronic cigarette liquid, the e-cigarette device operation, and user vaping preferences.

- The aerosol and gases produced by e-cigarettes contain nicotine, glycerin/glycols, artificial flavorings, and preservatives.

regarded as safe" in food products; however, their inhalation toxicity is unknown. To inform indoor air policies related to e-cigarettes, policy makers and public health officials need information on the potential health effects of indirect exposures to e-cigarette emissions.

\section{Understanding the Problem}

E-cigarettes are battery-powered devices that resemble traditional cigarettes and are designed to deliver nicotine to users. These devices typically operate by heating a liquid solution (called an e-liquid) composed of a humectant (e.g., propylene glycol or glycerol), nicotine, and flavoring agents. Various types of e-cigarettes are available. E-cigarettes are marketed to consumers online, in print, and on television. They are usually advertised as a healthier alternative to cigarette smoking, useful for quitting or reducing cigarette smoking, and a way for smokers to circumvent clean indoor air laws. From 2010 to 2011, e-cigarette awareness among 
all adults increased from about $41 \%$ to $58 \%$ and use nearly doubled (from about 3\% to 6\%). ${ }^{1}$ Since 2007 , e-cigarette sales have doubled every year, reaching annual sales of $\$ 1$ billion in August 2013.2

As e-cigarette use proliferates in the United States, research is needed to determine the potential health risks posed by indirect exposure to the aerosol and gases emitted by e-cigarettes. Although some studies have examined the chemical constituents of e-liquids, ${ }^{3-5}$ e-liquids are altered during the heating process and are converted into aerosol and gases that contain other potentially harmful constituents, such as aldehydes, polycyclic aromatic hydrocarbons, and metals.4,6 Little scientific evidence is available on the toxic chemical exposures posed by the use of e-cigarettes, 7,8 particularly for indoor secondhand and tertiary exposures in public places. ${ }^{9,10}$ Policy makers and public health officials need more information about the potential health impact of such indirect exposures to e-cigarette emissions to inform indoor air policies related to the use of these products. ${ }^{11}$

Recent research has started to characterize e-cigarette emissions, with an initial focus on understanding the exposure and dose received by the user. These studies used modified smoking machines or experimental systems to generate the emissions for sample collection and/or realtime characterization, $, 5,12-15$ or they injected emissions into a chamber for sample collection and/or real-time characterization. ${ }^{16}$ Only one study attempted to extrapolate the data collected in a chamber study to characterize secondhand exposure. 16 In a separate project, researchers collected and analyzed e-cigarette emissions dispersed into a 40-cubic-meter chamber (roughly the size of an 8 - by 10 -foot room), 17 but data quality and interpretation concerns raised questions about the accuracy and representativeness of the data for assessing secondhand exposures. ${ }^{18}$ To date, few studies of secondhand e-cigarette exposures have used realistic exposure conditions.

\section{Recent RTI Findings}

Our initial understanding of secondhand exposure is based on an understanding of the source-exposure-dose paradigm (see Figure 1) and an analysis of RTI's and other researchers' e-cigarette emissions characterization data. The exposure paradigm illustrates the critical factors that influence the nicotine dose received from primary, secondary, and tertiary exposure to e-cigarette emissions. The source of secondhand exposure is the aerosol and gases exhaled by the primary user. Tertiary exposure is caused by the residue deposited on surfaces and fabrics.

Our dosimetry modeling calculated that a teenage male e-cigarette user exhales $50 \%$ of the e-cigarette emissions that he inhaled. The devices and e-liquids themselves are the most important determinants of the physical and chemical characteristics of the exhaled aerosol and gases. The physiological conditions of our lungs, the quality of the device, and the composition of the e-liquid impact the aerosol size distribution (Figure 2) and chemical composition (Table 1) of the aerosol. The warm, humid conditions in our lungs prevent aerosol evaporation and actually promote aerosol formation. The trace quantities of metals potentially released by the heating coil, thermal oxidation of organic compounds' byproducts, artificial flavorings, and preservatives are additional important factors.

\section{Figure 1. Source-exposure-dose paradigm applied to secondhand exposure to e-cigarette emissions}

\section{Source}

Emission Generation
Number of users
Vaping topography
User profile
Device type and brand
Liquid brand

Emission Characteristics

Gas emission rate Aerosol emission rate Aerosol size distribution Aerosol chemistry
Exposure Transport Aerosol and Gas Aerosol evaporation Diffusional deposition Particle/gas partitioning Indoor Environment Air exchange rate Furnishings Number of occupants Occupant activities
Exposure Source

Primary

Secondhand

Tertiary

Exposure Route

Inhalation

Dermal

Exposure Concentration

Proximity

Activity patterns
Dose
Inhalation
Exposure source
Air concentration
Ventilation rate
Duration
Dermal
Surface loading
Contact area
Contact frequency
Number of contacts 


\section{Figure 2. Aerosol size distribution produced from two commercially available liquids as measured by an electrical mobility analyzer}

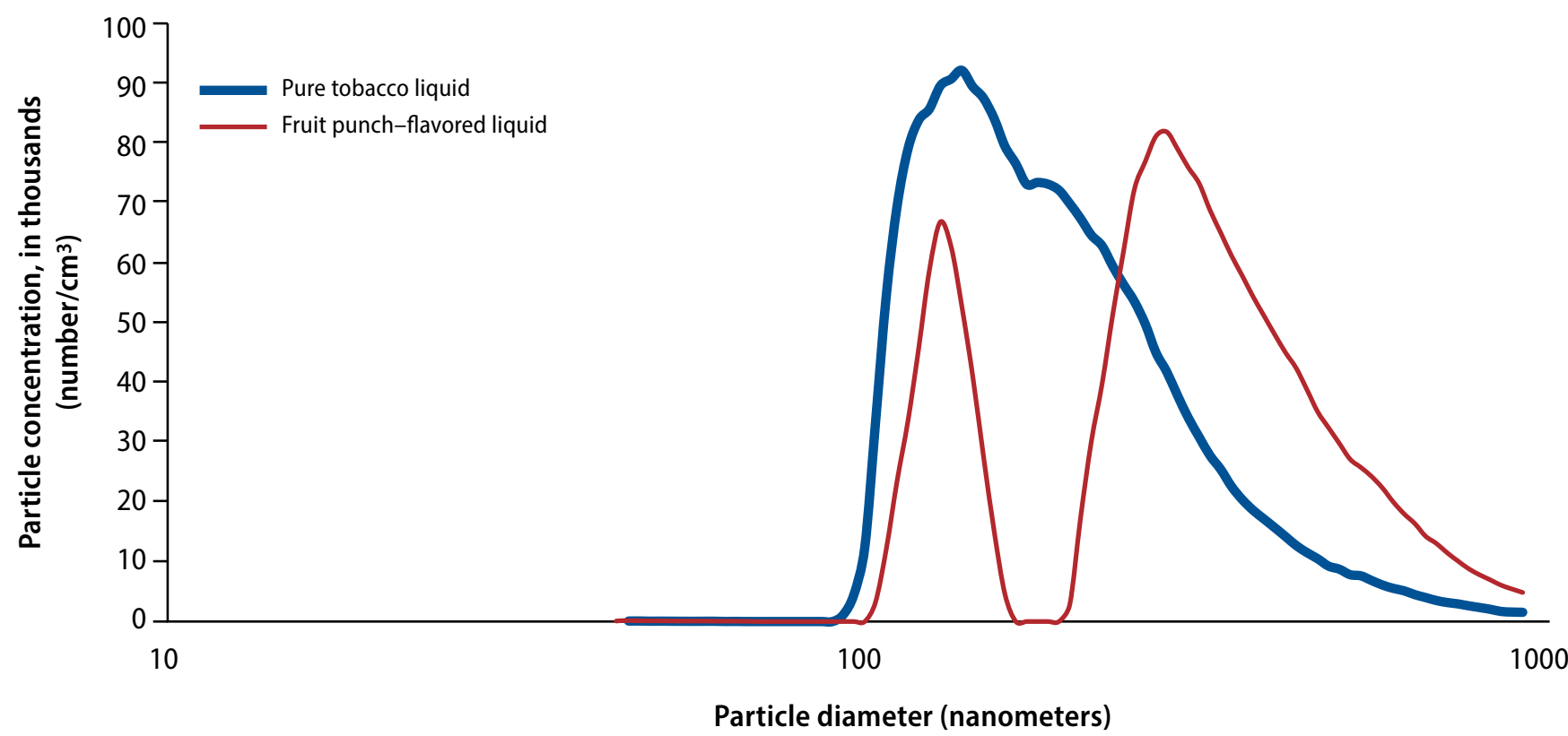

Note: The e-cigarette was connected to a temperature- and humidity-controlled chamber to simulate a user's respiratory system.

Table 1. Major chemical classes found in e-liquid and e-cigarette emissions

\begin{tabular}{llcccc} 
OChemical Class & Purpose & Active ingredient & $\bullet$ & $\bullet$ & $\bullet$ \\
\hline Nicotine & Carrier liquid & $\bullet$ & $\bullet$ & $\bullet$ \\
\hline Glycerin and glycol & Artificial flavoring & $\bullet$ & $\bullet$ & $\bullet$ \\
\hline Alkylated cyclic compoundsa & Preservative & $\bullet$ & $\bullet$ & $\bullet$ \\
\hline Phenolic compoundsb & Artificial coloring & $\bullet$ & & \\
\hline High-molecular-weight & & & & \\
aromaticsc & & & & \\
\hline
\end{tabular}

a Ethyl maltol, 2-methylnaphthalene, and 2-tert-butyl-p-cresol present.

b BHA and BHT present.

c Only in fruit punch-flavored liquid.

This finding is important because the nicotine partitioning between aerosol and gas affects the nicotine transport dynamics within a room and directly influences secondhand exposure; that is, the aerosol-gas distribution affects the dispersion of the nicotine within the room and how much nicotine is deposited on surfaces. These aerosol and gas transport dynamics are also influenced by user consumption behavior, as well as room conditions. ${ }^{9}$ E-cigarette aerosol concentrations inside a room are highly variable, fluctuating from background levels (fewer than 10 micrograms per cubic meter) to extremely high levels (10,000 micrograms per cubic meter) close to the user. Environmental factors, such as the air exchange rate, the location of air supply and return vents, the room size, movement of people in the room, and the placement and size of furnishings within the room, determine secondhand exposure.

\section{Future Research Needs}

To properly examine the potential health effects associated with e-cigarette use in public places, a variety of factors must be known. The design characteristics of e-cigarettes, such as pressure drop, flow rate, and aerosol density, differ significantly from traditional cigarettes and vary between e-cigarettes themselves,, 419 making standard testing protocols for traditional cigarette emissions inappropriate for e-cigarettes. ${ }^{6}$ Research suggests that variations in the engineering of e-cigarettes may influence the chemical toxins present in the emissions produced $7,15,19$ and, consequently, in the aerosol and gases exhaled by users. ${ }^{7}$ Therefore, new standards must be developed for conducting laboratory testing of e-cigarette emissions and secondhand exposures across multiple device types.

Understanding the potential risks posed by exposure to secondhand e-cigarette emissions is particularly complex due to the diversity of e-cigarette users' characteristics (e.g., experience level and inhalation/exhalation volume) and topography (e.g., frequency and duration of puffs). Users' consumption behavior affects both the operation of the e-cigarette devices and the physical and characteristics of the e-cigarette emissions that lead to secondhand exposure.4,20,21 Research 
that investigates the e-cigarette aerosol and gases inhaled and exhaled by the user must consider the physiologically relevant conditions inside the user's lungs, especially when e-cigarette emissions are artificially generated, because the additional aerosol formation and gas-particle partitioning will impact secondhand exposures. Further study is needed to determine which device engineering characteristics and liquid compositions might reduce or minimize potential secondhand exposures from e-cigarette use.

\section{References}

1. King BA, Alam S, Promoff G, Arrazola R, Dube SR. Awareness and everuse of electronic cigarettes among U.S. adults, 2010-2011. Nicotine Tob Res. 2013 Sep;15(9):1623-7.

2. Robehmed, N. E-cigarette sales surpass $\$ 1$ billion as big tobacco moves in. Forbes. 2013 September 17.

3. Etter JF, Zather E, Svensson S. Analysis of refill liquids for electronic cigarettes. Addiction. 2013 Sep;108(9):1671-9.

4. Cheng T. Chemical evaluation of electronic cigarettes. Tob Control. 2014 May;23 Suppl 2:ii11-7.

5. Westenberger, B. Evaluation of e-cigarettes. St. Louis, MO: Department of Health and Human Services, Food and Drug Administration, Center for Drug Evaluation and Research, Division of Pharmaceutical Analysis; (2009).

6. Brown CJ, Cheng JM. Electronic cigarettes: product characterisation and design considerations. Tob Control. 2014 May;23 Suppl 2:ii4-10.

7. Grana R, Benowitz N, Glantz SA. E-cigarettes: a scientific review. Circulation. 2014 May 13;129(19):1972-86.

8. Orr MS. Electronic cigarettes in the USA: a summary of available toxicology data and suggestions for the future. Tob Control. 2014 May;23 Suppl 2:ii18-ii22.

9. Callahan-Lyon P. Electronic cigarettes: human health effects. Tob Control. 2014 May;23 Suppl 2:ii36-40.

10. Kuschner WG, Reddy S, Mehrotra N, Paintal HS. Electronic cigarettes and thirdhand tobacco smoke: two emerging health care challenges for the primary care provider. Int J Gen Med. 2011;4:115-20.

11. Schmitt CL, Lee YO, Curry LE, Farrelly MC, Rogers T. Research support for effective state and community tobacco control programme response to electronic nicotine delivery systems. Tob Control. 2014;23 Suppl 3:iii54-7.

12. Cobb NK, Byron MJ, Abrams DB, Shields PG. Novel nicotine delivery systems and public health: the rise of the "e-cigarette." Am J Pub Health. 2010 Dec;100(12):2340-2.

13. Trehy ML, Ye W, Hadwiger ME, Moore TW, Allgire JF, Woodruff JT, Ahadi SS, Black JC, Westenberger BJ. Analysis of electronic cigarette cartridges, refill solutions, and smoke for nicotine and nicotine related impurities. J Liq Chromatogr Relat Technol. 2011;34:1442-58.

14. Pellegrino RM, Tinghino B, Mangiaracina G, Marani A, Vitali M, Protano C, et al. Electronic cigarettes: an evaluation of exposure to chemicals and fine particulate matter (PM). Annali di Igiene : Medicina Preventiva e di Comunita. 2012 Jul-Aug;24(4):279-88.
15. Goniewicz ML, Kuma T, Gawron M, Knysak J, Kosmider L. Nicotine levels in electronic cigarettes. Nicotine Tob Res. 2013 Jan;15(1):158-66.

16. Schripp T, Markewitz D, Uhde E, Salthammer T. Does e-cigarette consumption cause passive vaping? Indoor Air. 2013 Feb;23(1):25-31.

17. McAuley TR, Hopke PK, Zhao J, Babaian S. Comparison of the effects of e-cigarette vapor and cigarette smoke on indoor air quality. Inhalation Toxicology. 2012 Oct;24(12):850-7.

18. Burstyn I. Peering through the mist: systematic review of what the chemistry of contaminants in electronic cigarettes tells us about health risks. BMC Public Health. 2014;14:18.

19. Williams M, Talbot P. Variability among electronic cigarettes in the pressure drop, airflow rate, and aerosol production. Nicotine Tob Res. 2011 Dec;13(12):1276-83.

20. Evans SE, Hoffman AC. Electronic cigarettes: abuse liability, topography and subjective effects. Tob Control. 2014 May;23 Suppl 2:ii23-9.

21 Farsalinos KE, Spyrou A, Tsimopoulou K, Stefopoulos C, Romagna G, Voudris V. Nicotine absorption from electronic cigarette use: comparison between first and new-generation devices. Scientific Reports. 2014;4:4133.

\section{About the Authors}

Jonathan Thornburg, PhD, is director of Exposure and Aerosol Technology at RTI International. His research interests are personal exposure to aerosols generated in indoor or outdoor environments, and the environmental fate of these aerosols.

Quentin Malloy, PhD, is an aerosol engineer at RTI. His research interests are aerosol chemistry and instrumentation and their relationship to personal exposure.

Seung-Hyun Cho, PhD, is an aerosol engineer at RTI. Her research interests are personal exposure to aerosols and gases, and deposition within a person's respiratory tract.

William Studabaker, PhD, is the manager of RTI's Trace Organic Chemistry program. His specialty is analytical chemistry methods for detection of trace organics in environmental and biological samples.

Youn Ok Lee, PhD, is a public health analyst at RTI. Her research interests include the implications of tobacco and vapor product marketing and design on public policy, regulation, and health behavior.

RTI Press Research Briefs and Policy Briefs are scholarly essays on policy, methods, or other topics relevant to RTI areas of research or technical focus.

RTI International, 3040 East Cornwallis Road, PO Box 12194 Research Triangle Park, NC 27709-2194 USA

$919.541 .6000 \quad$ rtipress@rti.org www.rti.org

o2015 Research Triangle Institute. RTI International is a registered trademark and a trade name of Research Triangle Institute.

All rights reserved. This brief is protected by copyright. Credit must be provided to the author and source of the document when the content is quoted. Neither the document nor partial or entire reproductions may be sold without prior written permission from the publisher.

RTI Press publication RB-0008-1503

www.rti.org/rtipress 